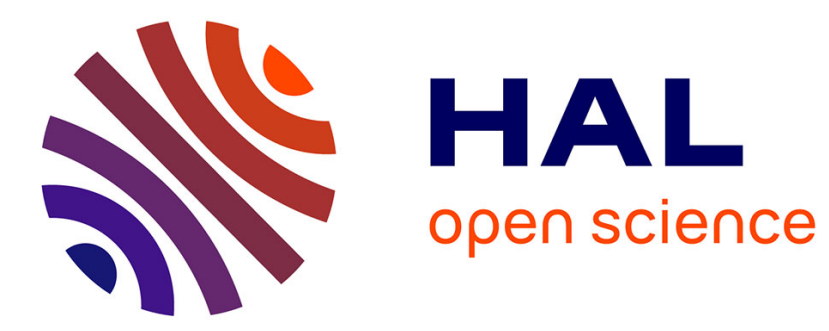

\title{
Thermodynamic Description of Bis-urea Self-Assembly: Competition between Two Supramolecular Polymers
}

\author{
Mathilde Bellot, Laurent Bouteiller
}

\section{To cite this version:}

Mathilde Bellot, Laurent Bouteiller. Thermodynamic Description of Bis-urea Self-Assembly: Competition between Two Supramolecular Polymers. Langmuir, 2008, 24 (24), pp.14176-14182. 10.1021/la802367r . hal-01696727

\section{HAL Id: hal-01696727 https://hal.science/hal-01696727}

Submitted on 29 Aug 2020

HAL is a multi-disciplinary open access archive for the deposit and dissemination of scientific research documents, whether they are published or not. The documents may come from teaching and research institutions in France or abroad, or from public or private research centers.
L'archive ouverte pluridisciplinaire HAL, est destinée au dépôt et à la diffusion de documents scientifiques de niveau recherche, publiés ou non, émanant des établissements d'enseignement et de recherche français ou étrangers, des laboratoires publics ou privés. 


\title{
Thermodynamic description of bis-urea self-assembly: competition between two supramolecular polymers
}

\author{
Mathilde Bellot ${ }^{\text {thb }}$, Laurent Bouteiller ${ }^{\text {ab }}$ \\ . UPMC Univ Paris 06, UMR 7610, Chimie des Polymères, F-75005, Paris, France \\ ${ }^{\circ}$ CNRS, UMR 7610, Chimie des Polymères, F-75005, Paris, France
}

E-mail: laurent.bouteiller@upmc.fr

\begin{abstract}
Supramolecular polymers are chains of small molecules held together through reversible noncovalent interactions. In general, a given monomer self-assembles into a single type of supramolecular polymer. However, in few cases, two different self-assembled structures can co-exist: this yields interesting responsive systems. In order to improve the understanding of these systems, we report an association model describing the self-assembly of a supramolecular polymer into two competing forms. The parameters controlling the system have been measured by high sensitivity differential scanning calorimetry (DSC) and isothermal titration calorimetry (ITC) in the case of a hydrogen-bonded bis-urea supramolecular polymer solution in toluene. The model enables to compute the proportion and length of all components in the system at any temperature and concentration. The results of these calculations are in agreement with the experimental phase diagram and with independent viscosity measurements.
\end{abstract}




\section{Introduction}

Supramolecular polymers are chains of small molecules held together through reversible non-covalent interactions. ${ }^{1-4}$ The dynamic character of the interaction is responsible for the appearance of new properties, as compared to those of usual covalent polymers. For example, these materials may exhibit self-healing behavior.5 Moreover, they can display polymer-like properties (such as viscoelasticity) under some experimental conditions and oligomer-like properties under other conditions. For instance, a material with a high molar mass at room temperature and a low molar mass at higher temperature is potentially useful for a wide range of applications.

In this context, we have previously reported a bis-urea based monomer (EHUT) which self-assembles in non-polar solvents into two distinct dynamic supramolecular polymer structures (Figure 1a). ${ }^{6}$ At high temperatures, long hydrogen bonded filaments with a single molecule in the cross-section are formed. At lower temperatures, the bis-ureas reorganize into very long and rigid tubes with three molecules in the cross-section. ${ }^{78}$ The entanglement and the dynamic character of these long tubes are responsible for viscoelastic properties ${ }^{9,10}$ which can be useful for applications in domains such as cosmetics."

Because many properties of supramolecular polymers derive from the length of the chains, it is particularly relevant to be able to characterize their length. However, this is not a trivial task because of the dynamic nature of the assemblies. ${ }^{4}$ Direct techniques such as size exclusion chromatography or MALDI mass spectroscopy are not suitable because the molar mass of supramolecular polymers depends on the actual conditions of the analysis (temperature, solvent, concentration). The best approach is then to consider all the possible self-assembled species present and establish a theoretical model including equilibrium constants linking the concentration of the different species. ${ }^{12}$ Experimental determination of the equilibrium constants makes it possible to compute the composition and average molar mass at any concentration. Such an approach has been successfully implemented in the case of the formation of linear chains through isodesmic,$^{13-17}$ cooperative $^{18-21}$ or anticooperative ${ }^{22}$ processes. The cases of supramolecular copolymers ${ }^{23}$ or macrocycles ${ }^{22-26}$ has also been considered. The effect of a competition between two linear supramolecular polymers in equilibrium has been much less considered. ${ }^{27}$ In particular, to our knowledge, no mass action law approach has been described. Consequently, the aims of this paper are (i) to establish the relevant equations governing a system of two supramolecular polymers in equilibrium, (ii) to show an experimental approach based on high sensitivity differential 
scanning calorimetry (DSC) and isothermal titration calorimetry (ITC) in order to determine the thermodynamic parameters of the system, and (iii) to apply this approach to improve our understanding of the particular supramolecular polymers formed by bis-urea EHUT in toluene.

\section{Experimental Section}

Solvents were used as received. Solutions were prepared under stirring at room temperature, at least 1day prior to use.

DSC. Thermograms were measured using a N-DSC III instrument from CSC. The reference cell was filled with toluene and the sample cell $(0.3 \mathrm{~mL})$ with EHUT solution. The capillary cells were not capped, and a constant pressure of $610^{5} \mathrm{~Pa}$ was applied. A baseline scan (toluene in both reference and sample cells) was systematically performed in identical conditions and subtracted from the sample scan. Transition temperature $\left(\mathrm{T}^{* *}\right)$ and enthalpy $\left(\Delta \mathrm{H}^{* *}\right)$ were taken as the average of heating and cooling scans, at a scan rate of $1^{\circ} \mathrm{C} / \mathrm{min}$ (unless specified otherwise).

ITC. Heats of dissociation were measured using a MicroCal VP-ITC titration microcalorimeter. The experimental conditions have been described previously. ${ }^{28}$

\section{Results and Discussion}

Association model. The self-association of a monomer (M) into two supramolecular polymers in equilibrium ( $F_{n}$ and $T_{n}$ ) can be described by the infinite set of equilibria mentioned on Figure 1b. In chloroform solution, bis-urea EHUT has been shown to self-assemble into a single supramolecular polymer (filament, $F_{n}$ ), and to obey a cooperative self-association model such that the dimerization step is less favored than the subsequent association steps. Moreover, the latter can be considered to be independent of $n .{ }^{19628}$ In toluene solution, bis-urea EHUT has been shown to self-assemble into two supramolecular polymers: long filaments of the same structure than in chloroform (with a single molecule in the cross-section) together with very long and rigid tubes (with three molecules in the cross-section). ${ }^{6.8}$ Therefore, the simplest association model that can possibly describe this system comprises a cooperative self-association model for each supramolecular polymer, with $\mathrm{k}_{\mathrm{n}}=\mathrm{k}$ for $\mathrm{n}>2$ and $\mathrm{k}>\mathrm{k}_{2}$ in the case of filaments $\left(\mathrm{F}_{\mathrm{n}}\right)$, and with $\mathrm{K}_{\mathrm{n}}=\mathrm{K}$ for $\mathrm{n}>2$ and $\mathrm{K}>\mathrm{K}_{2}$ in the case of tubes $\left(\mathrm{T}_{\mathrm{n}}\right)_{.2930}$ 
a)

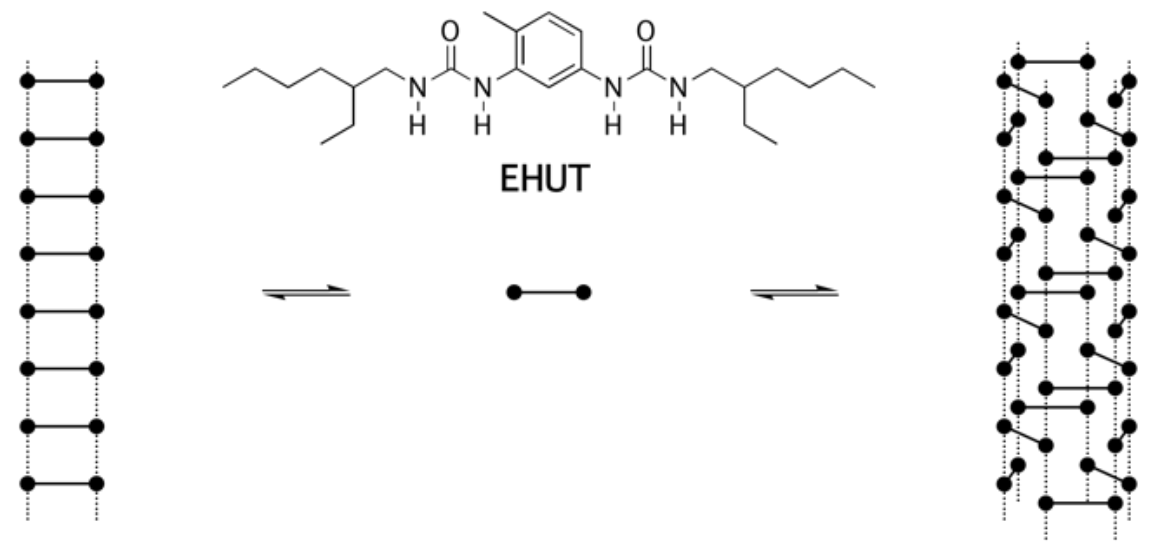

b)

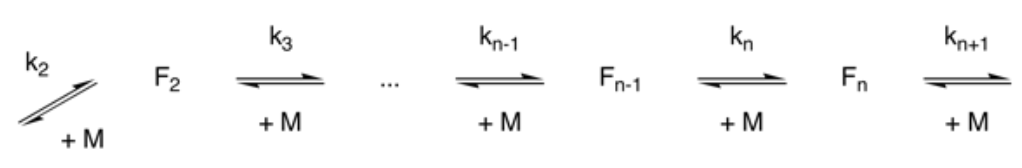

M

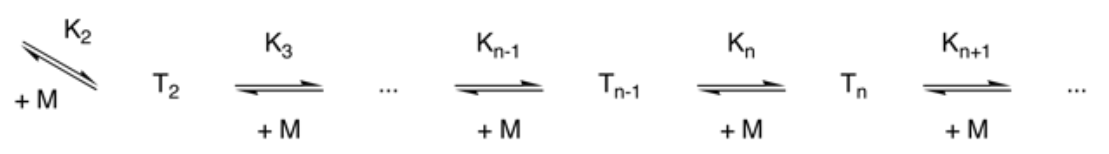

Figure 1. (a) EHUT monomer and schematic structure for filaments and tubes. Hydrogen bonds are represented by dotted lines connecting the urea functions (black circles). A more precise supramolecular model for tubes can be found in reference 8. (b) Association equilibria between monomer (M) and two supramolecular polymers $\left(\mathrm{F}_{\mathrm{n}}\right.$ and $\left.\mathrm{T}_{\mathrm{n}}\right)$ of degree of polymerization $\mathrm{n}$.

Within this model, the concentration of all supramolecular chains can be expressed by applying the mass action law.

$$
\begin{aligned}
& {\left[F_{n}\right]=k_{2} k^{n-2}[M]^{n}, \quad \text { for } n \geq 2} \\
& {\left[T_{n}\right]=K_{2} K^{n-2}[M]^{n}, \text { for } n \geq 2}
\end{aligned}
$$

Conservation of mass then yields the following equation

$$
\frac{\mathrm{k}_{2}}{\mathrm{k}} \frac{[\mathrm{M}]}{(1-\mathrm{k}[\mathrm{M}])^{2}}+\frac{\mathrm{K}_{2}}{\mathrm{~K}} \frac{[\mathrm{M}]}{(1-\mathrm{K}[\mathrm{M}])^{2}}+\left(1-\frac{\mathrm{k}_{2}}{\mathrm{k}}-\frac{\mathrm{K}_{2}}{\mathrm{~K}}\right)[\mathrm{M}]-\mathrm{C}_{0}=0
$$

In this approach, the formation of cyclics is neglected, which is justified by the rigidity of the assemblies. The free monomer concentration ([M]) can be determined numerically from eq (3), if $\mathrm{k}_{2}, \mathrm{k}$, 
$\mathrm{K}_{2}, \mathrm{~K}$ and the overall concentration $\left(\mathrm{C}_{0}\right)$ are known. Through eq (1) and (2), the whole molecular weight distributions can then be determined.

The temperature dependence can be introduced through the van't Hoff equations, if the enthalpies of association $\left(\Delta \mathrm{h}_{2}, \Delta \mathrm{h}, \Delta \mathrm{H}_{2}\right.$ and $\left.\Delta \mathrm{H}\right)$ are assumed to be temperature independent.

$$
\begin{aligned}
& \mathrm{k}_{2}(T)=\mathrm{k}_{2}\left(\mathrm{~T}_{0}\right) \exp \left(\frac{\Delta \mathrm{h}_{2}}{\mathrm{R}}\left(\frac{1}{\mathrm{~T}_{0}}-\frac{1}{\mathrm{~T}}\right)\right) \\
& \mathrm{k}(\mathrm{T})=\mathrm{k}\left(\mathrm{T}_{0}\right) \exp \left(\frac{\Delta \mathrm{h}}{\mathrm{R}}\left(\frac{1}{\mathrm{~T}_{0}}-\frac{1}{\mathrm{~T}}\right)\right) \\
& \left.\mathrm{K}_{2}(\mathrm{~T})=\mathrm{K}_{2}\left(\mathrm{~T}_{0}\right) \exp \frac{\Delta \mathrm{H}_{2}}{\mathrm{R}}\left(\frac{1}{\mathrm{~T}_{0}}-\frac{1}{\mathrm{~T}}\right)\right)(6) \\
& \mathrm{K}(\mathrm{T})=\mathrm{K}\left(\mathrm{T}_{0}\right) \exp \left(\frac{\Delta \mathrm{H}}{\mathrm{R}}\left(\frac{1}{\mathrm{~T}_{0}}-\frac{1}{\mathrm{~T}}\right)\right)
\end{aligned}
$$

Thus, the knowledge of eight parameters - the association constants at a given temperature $\mathrm{T}_{0}\left(\mathrm{k}_{2}\left(\mathrm{~T}_{0}\right)\right.$, $\left.\mathrm{k}\left(\mathrm{T}_{0}\right), \mathrm{K}_{2}\left(\mathrm{~T}_{0}\right), \mathrm{K}\left(\mathrm{T}_{0}\right)\right)$ and the corresponding enthalpies of association $\left(\Delta \mathrm{h}_{2}, \Delta \mathrm{h}, \Delta \mathrm{H}_{2}, \Delta \mathrm{H}\right)$ - is necessary to compute the concentrations of all filaments, tubes and monomer species present in the solution at any total concentration $\mathrm{C}_{0}$ and temperature $\mathrm{T}$.

Determination of parameters. Isothermal titration calorimetry (ITC) was previously described as an efficient technique to determine the parameters for the self-assembly of EHUT into filaments and of supramolecular polymers in general ${ }^{28}$ The principle is to measure the heat exchanged while aliquots of a relatively concentrated supramolecular polymer solution are injected into pure solvent. The heat absorbed is proportional to the number of hydrogen bonds broken during the dilution, and is thus directly related to the enthalpy of association and the association constants describing the system. When only one supramolecular polymer is present, an ITC experiment performed at a temperature $\mathrm{T}_{0}$ yields $\mathrm{k}_{2}\left(\mathrm{~T}_{0}\right), \mathrm{k}\left(\mathrm{T}_{0}\right)$, and $\Delta \mathrm{h}{ }^{28}$ Consequently, this technique was considered for the present system: equations (1) to (3) were used to calculate the heat evolved during an ITC experiment, by dilution of a mixture of two supramolecular polymers in equilibrium $\left(\mathrm{F}_{\mathrm{n}}\right.$ and $\mathrm{T}_{\mathrm{n}}$ ) (see Supporting Information). Unfortunately, the parameters $\left(\mathrm{k}_{2}\left(\mathrm{~T}_{0}\right), \mathrm{k}\left(\mathrm{T}_{0}\right), \mathrm{K}_{2}\left(\mathrm{~T}_{0}\right), \mathrm{K}\left(\mathrm{T}_{0}\right), \Delta \mathrm{h}_{2}, \Delta \mathrm{h}, \Delta \mathrm{H}_{2}\right.$ and $\left.\Delta \mathrm{H}\right)$ are too numerous to be reliably determined from an ITC experimental data set, even if the experiments are performed at several temperatures (data 
not shown). Consequently, high sensitivity DSC was considered as an additional technique in order to try and determine some of the parameters independently from ITC.

The sensitivity of current DSC instruments makes it possible to probe very dilute solutions. In particular, high sensitivity DSC is widely used to characterize cooperative transitions in biological macromolecules such as protein folding." In the case of solutions of synthetic macromolecular or supramolecular systems in organic solvents, the use of DSC is much less developed. Although the use of classical DSC to characterize moderately concentrated solutions has been reported, ${ }^{32.33}$ previous high sensitivity DSC study on very dilute (typically below $10^{-3} \mathrm{~mol} / \mathrm{L}$ or $1 \mathrm{~g} / \mathrm{L}$ ) supramolecular systems in non polar organic solvents are very rare. ${ }^{21,34}$ Therefore, we decided to perform a thorough DSC study, including the influence of concentration and scan rate, on the present bis-urea system. Figure 2a shows the variation of heat capacity with temperature for a 5mM EHUT solution in toluene. As will be shown below, the endothermal peak at $42^{\circ} \mathrm{C}$ is due to the reorganization of supramolecular tubes $\left(\mathrm{T}_{\mathrm{n}}\right)$ into filaments $\left(\mathrm{F}_{\mathrm{n}}\right)$. After subtraction of the heat capacity of pure toluene and concentration normalization, the molar heat capacity of EHUT is obtained (Figure 2b).

Several comments can be made at this point. First, the transition is perfectly reversible, because the cooling scan is symmetrical to the heating scan and the scans are identical for at least 6 cycles of heating and cooling (see Figure S1). Secondly, there is a limited scan rate dependence: above $0.2^{\circ} \mathrm{C} / \mathrm{min}$, the curve is slightly broadened (Figure $2 \mathrm{~b}$ ). Therefore, if the shape of the curve is to be analyzed in thermodynamic terms (free from any kinetic effect), ${ }^{31}$ a scan rate below $0.2^{\circ} \mathrm{C} / \mathrm{min}$ is recommended. However, both the transition temperature (the maximum of the curve, $\mathrm{T}^{* *}$ ) and the enthalpy of the transition (the area under the curve, $\Delta \mathrm{H}^{* *}$ ) are constant in the same scan rate range (Figures S2 and S3). Consequently, a scan rate of $1^{\circ} \mathrm{C} / \mathrm{min}$ can be used for faster determination of $\mathrm{T}^{* *}$ and $\Delta \mathrm{H}^{* *}$. Thirdly, the curve at the transition shows a large endothermic peak, but no heat capacity jump: this means that there is no difference in heat capacity between the tube and the filament forms $\left(\Delta \mathrm{C}_{\mathrm{p}}^{* *}=0\right)$, and justifies the previous assumption that the enthalpies of association $\left(\Delta \mathrm{h}_{2}, \Delta \mathrm{h}, \Delta \mathrm{H}_{2}\right.$ and $\Delta \mathrm{H})$ are temperature independent. 

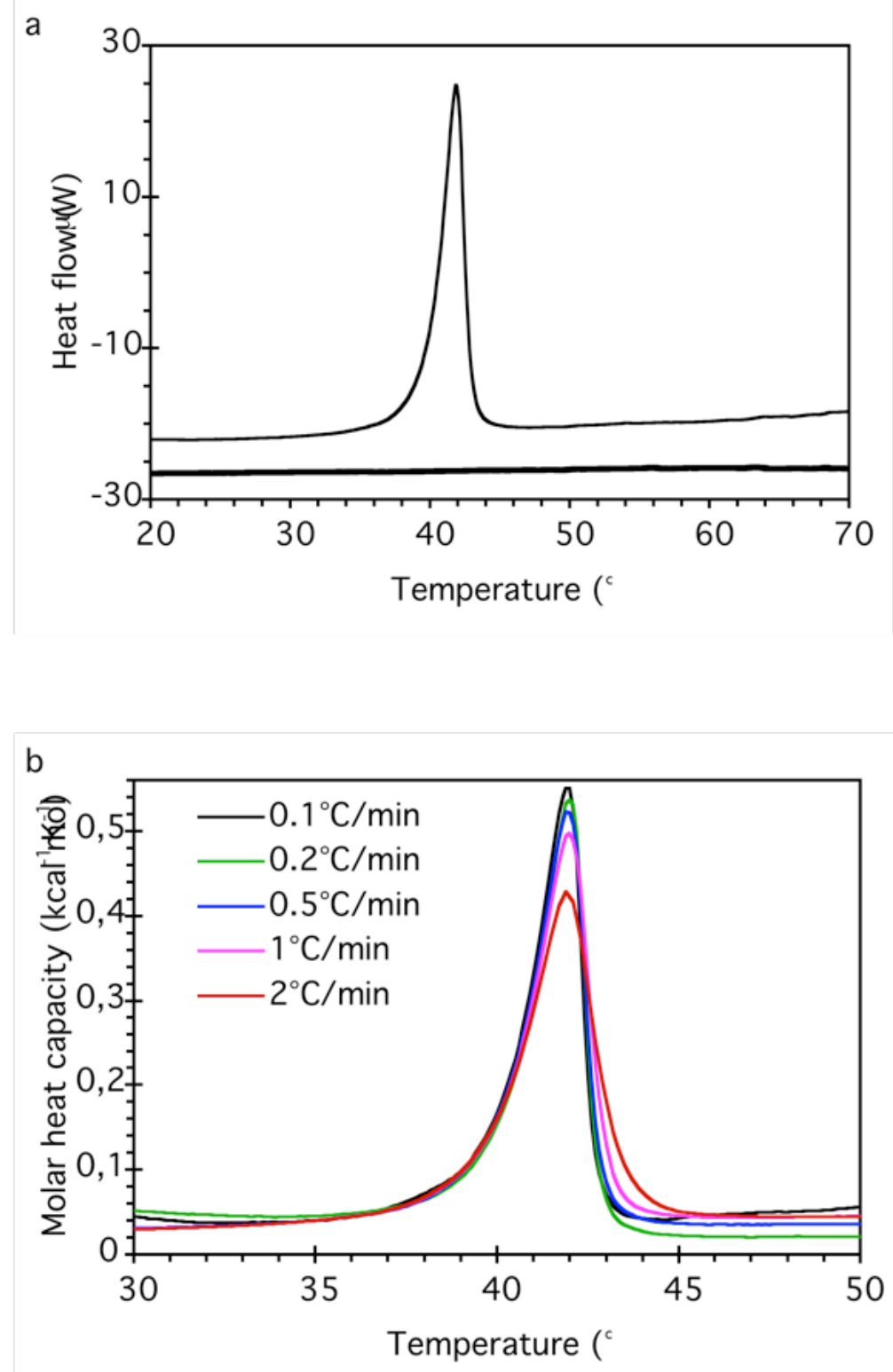

Figure 2. DSC thermograms (second heating) of a 5mM EHUT solution in toluene. (a) Raw data (plain curve) and baseline (bold curve) at $1^{\circ} \mathrm{C} / \mathrm{min}$. (b) Baseline subtracted data at several heating rates. 


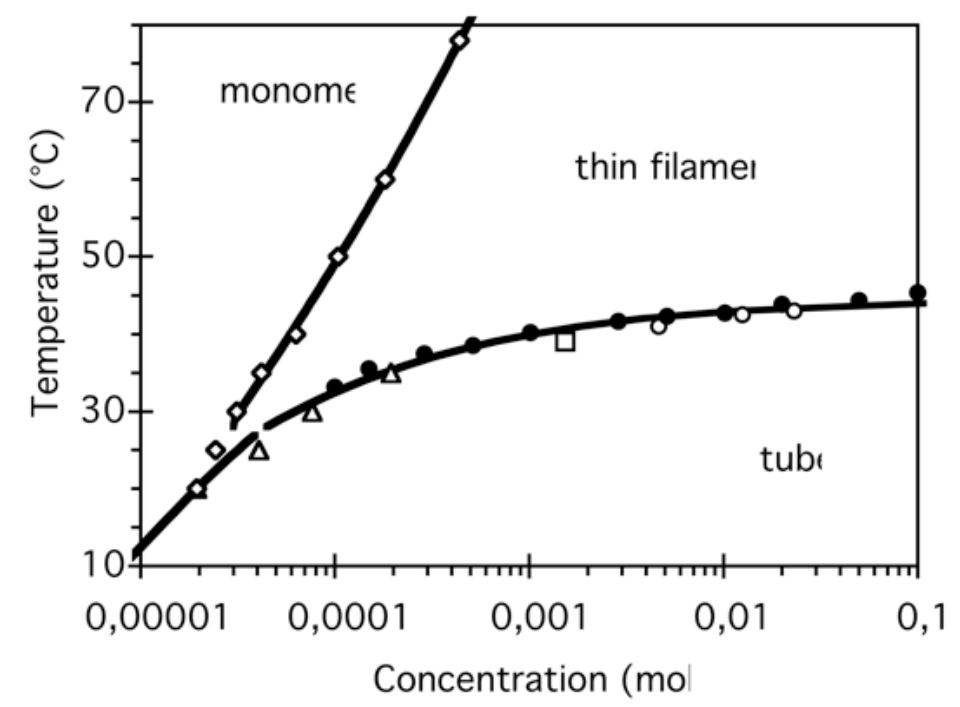

Figure 3. Pseudophase diagram for EHUT solutions in toluene. Transition between monomers and supramolecular filaments determined by ITC $(\diamond)$. Transition between filaments and tubes determined by ITC $(\Delta)$, viscosimetry $(\square)$, FTIR (o) or DSC $(\bullet)$. Curves: calculated transition based on parameter values in Table 1.

Next, the concentration dependence of the transition temperature is shown on Figure 3: $\mathrm{T}^{* *}$ increases moderately with concentration in the range $10^{4}$ to $10^{-1} \mathrm{~mol} / \mathrm{L}$. Figure 3 also shows that the transition measured by DSC indeed corresponds to the transition between tubes and filaments, because there is a perfect agreement with previous data from other techniques. ${ }^{6}$ The usefulness of DSC analysis is here clearly demonstrated: data can be obtained over a range of concentration of 3 orders of magnitude, filling the gap between ITC and FTIR data. ${ }^{35}$ Moreover, DSC gives a direct measure of the transition enthalpy: its concentration dependence is shown on Figure 4. The points corresponding to the concentrations above $10 \mathrm{mM}$ show some scatter, probably because the gels formed at these concentrations are quite strong, which makes it difficult to obtain perfectly homogeneous samples, and thus precise concentrations. At concentrations below $1 \mathrm{mM}$, the values for $\Delta \mathrm{H}^{* *}$ apparently decrease, but it is difficult to be sure that this is not simply due to the lower signal over noise ratio and the difficulty to define a perfect integration baseline. Consequently, between 1 and $10 \mathrm{mM}$, the data seems the most reliable and an average value of $\Delta \mathrm{H}^{* *}=1.2 \pm 0.2 \mathrm{kcal} / \mathrm{mol}$ can be determined. This enthalpy 
for the transition between tubes and filaments $\left(\Delta \mathrm{H}^{* *}\right)$ is a complex combination of the enthalpies for the transitions between monomer and filaments $\left(\Delta \mathrm{h}_{2}\right.$ and $\left.\Delta \mathrm{h}\right)$ and between monomer and tubes $\left(\Delta \mathrm{H}_{2}\right.$ and $\Delta \mathrm{H})$. However, if dimers are neglected compared to longer oligomers, then $\Delta \mathrm{H}^{* *}=\Delta \mathrm{h}-\Delta \mathrm{H}$.

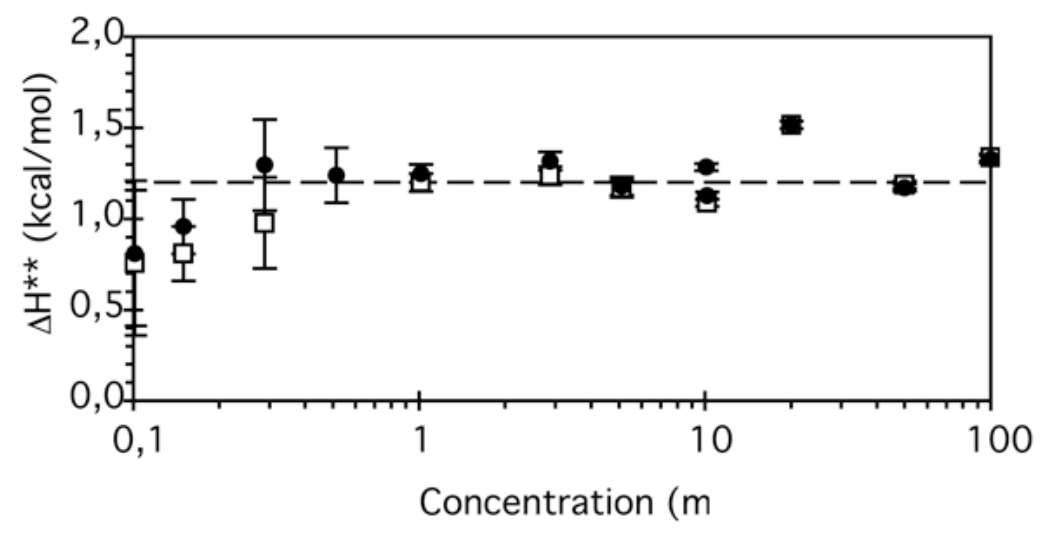

Figure 4. Enthalpy of the transition between tubes and filaments for solutions of EHUT in toluene, versus concentration. The values are measured by DSC (average of heating and cooling scans), at 0.1 $(\square)$ or $1^{\circ} \mathrm{C} / \min (\bullet)$. The error bars reflect the uncertainty for peak integration.

This information can now be used to fit the association model to the ITC data. Figure 5 shows the experimental ITC data obtained by diluting EHUT solutions into pure toluene at several temperatures. The 8 experimental curves were simultaneously fitted, with $\mathrm{k}_{2}\left(25^{\circ} \mathrm{C}\right), \mathrm{k}\left(25^{\circ} \mathrm{C}\right), \mathrm{K}_{2}\left(25^{\circ} \mathrm{C}\right), \mathrm{K}\left(25^{\circ} \mathrm{C}\right)$, $\Delta \mathrm{h}_{2}, \Delta \mathrm{h}, \Delta \mathrm{H}_{2}$ and $\Delta \mathrm{H}$ as parameters. Several fitting procedures were tested and are summarized in Table S1. Using a single constraint $\left(\Delta \mathrm{H}=\Delta \mathrm{h}-\Delta \mathrm{H}^{* *}\right)$ yields a good fit, but an unreasonably large value for $\Delta \mathrm{H}_{2}$. Therefore a second constraint was introduced: the value for $\Delta \mathrm{H}_{2}$ was fixed to extreme values, either $\Delta \mathrm{H}_{2}=\Delta \mathrm{H}$, or $\Delta \mathrm{H}_{2}=0 .{ }^{36}$ In both cases, a very good fit was obtained (similar $\chi^{2}$ ), with values for the other parameters barely affected by the value of $\Delta \mathrm{H}_{2}$ (entries 2 and 3 in Table $\mathrm{S} 1$ ). This means that it is not possible to determine a reliable value for $\Delta \mathrm{H}_{2}$ by this procedure, but that the other parameters can still 
be evaluated. The values adopted for the parameters are the average of the two fits and are reported in Table 1. Considering the excellent repeatability of the ITC data, and the negligible influence of $\Delta \mathrm{H}_{2}$, the largest uncertainty comes from the value of the constraint $\left(\Delta \mathrm{H}^{* *}\right)$. Therefore, the uncertainty was evaluated by performing other fits with extreme values for $\Delta \mathrm{H}^{* *}$, and are reported in Table 1.

The consistency of the model and parameter values can be checked by comparing the calculated phase diagram to the experimental phase diagram. The transition between filaments and tubes was defined as the temperatures and concentrations such that the total filament concentration is equal to the total tube concentration: $\sum_{n=2}^{\infty} n\left[F_{n}\right]=\sum_{n=2}^{\infty} n\left[T_{n}\right]$ with $[M]<\sum_{n=2}^{\infty} n\left[F_{n}\right]$. The other transitions were defined in the same manner. ${ }^{37}$ Figure 3 shows that the agreement between the model and the experiment is excellent. This is not surprising for the monomer to filament transition, as both the model and the experimental values are based on the same ITC data; however, the fact that the transition between filaments and tubes is correctly predicted by the model, in a concentration range where no ITC data was available, is clearly a good test of the model.

\begin{tabular}{llllll}
\hline $\mathrm{k}_{2}\left(25^{\circ} \mathrm{C}\right)$ & $\mathrm{k}\left(25^{\circ} \mathrm{C}\right)$ & $\mathrm{K}_{2}\left(25^{\circ} \mathrm{C}\right)$ & $\mathrm{K}\left(25^{\circ} \mathrm{C}\right)$ & $\mathrm{k}^{2} / \mathrm{K}_{2}$ & $\mathrm{~K}^{2} / \mathrm{K}_{2}$ \\
$(\mathrm{~L} / \mathrm{mol})$ & $(\mathrm{L} / \mathrm{mol})$ & $(\mathrm{L} / \mathrm{mol})$ & $(\mathrm{L} / \mathrm{mol})$ & $(\mathrm{L} / \mathrm{mol})$ & $(\mathrm{L} / \mathrm{mol})$ \\
\hline 820 & 76950 & 0.24 & 87110 & $7.210^{\circ}$ & $3.110^{10}$ \\
\pm 160 & \pm 760 & \pm 0.5 & \pm 540 & & \\
\hline$\Delta \mathrm{h}_{2}$ & $\Delta \mathrm{h}$ & $\Delta \mathrm{H}_{2}$ & $\Delta \mathrm{H}$ & $\mathrm{k} / \mathrm{k}_{2}$ & $\mathrm{~K} / \mathrm{K}_{2}$ \\
$(\mathrm{kcal} / \mathrm{mol})$ & $(\mathrm{kcal} / \mathrm{mol})$ & $(\mathrm{kcal} / \mathrm{mol})$ & $(\mathrm{kcal} / \mathrm{mol})$ & & \\
\hline-10.5 & -11.6 & -6 & -12.8 & 94 & $3.610^{5}$ \\
\pm 1.3 & \pm 0.1 & \pm 6 & \pm 0.2 & & \\
\hline
\end{tabular}

Table 1. Parameter values obtained by fitting the ITC data of Figure 5 and used in the simulations. 


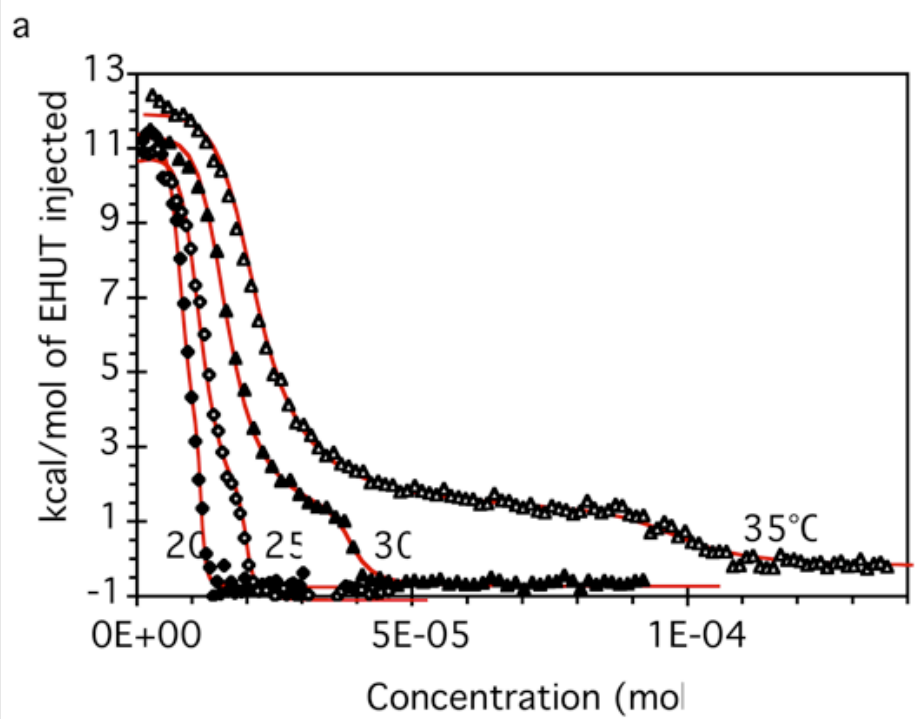

b

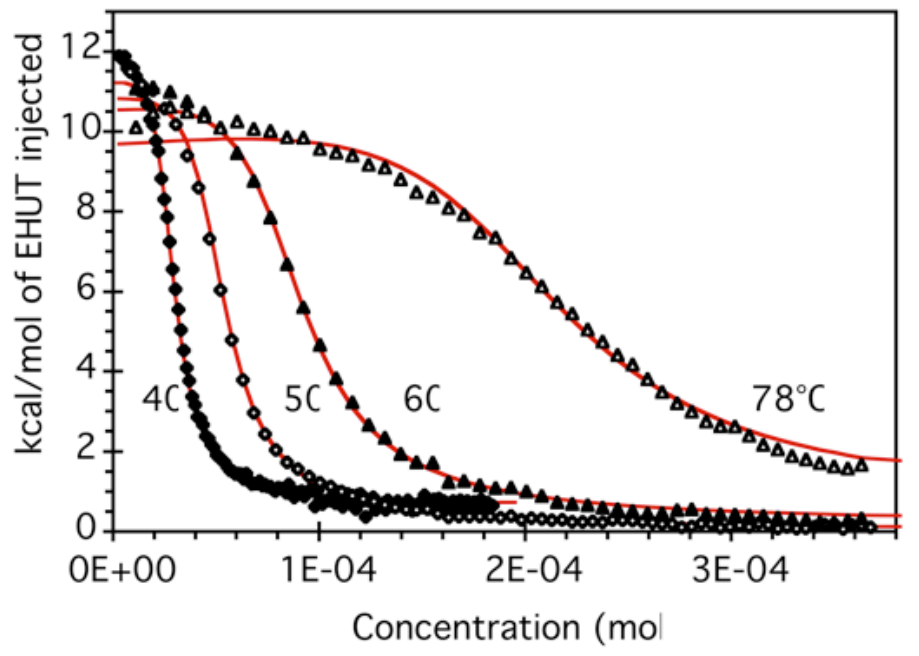

Figure 5. Experimental ITC enthalpograms (points) for EHUT solutions in toluene injected into pure toluene, versus total EHUT concentration in the cell. Conditions (temperature, [EHUT], injection volume): (a) (•): $20^{\circ} \mathrm{C}, 0.25 \mathrm{mM}, 4 \mu \mathrm{L} ;(\diamond): 25^{\circ} \mathrm{C}, 0.25 \mathrm{mM}, 5 \mu \mathrm{L} ;(\Delta): 30^{\circ} \mathrm{C}, 0.5 \mathrm{mM}, 5 \mu \mathrm{L} ;(\Delta): 35^{\circ} \mathrm{C}$ $1 \mathrm{mM}, 2 \mu \mathrm{L} ;(\mathrm{b})(\diamond): 40^{\circ} \mathrm{C}, 1 \mathrm{mM}, 2 \mu \mathrm{L} ;(\diamond): 50^{\circ} \mathrm{C}, 2 \mathrm{mM}, 4 \mu \mathrm{L} ;(\Delta): 60^{\circ} \mathrm{C}, 2 \mathrm{mM}, 6 \mu \mathrm{L} ;(\Delta): 78^{\circ} \mathrm{C}, 2 \mathrm{mM}$, $6 \mu \mathrm{L}$. Calculated ITC enthalpograms (curves) based on the association model (Figure 1) and the parameter values in Table 1. 
Description of bis-urea self-assembly. The association model can now be used to visualize the composition of solutions and degree of polymerization of EHUT filaments and tubes at different temperatures and overall concentrations. Figures 6 and 7 show respectively the weight fractions of monomer, filaments and tubes versus concentration (Figure 6) or temperature (Figure 7). Figures S8 and S9 show that the simulations are quite reliable: taking parameter values from the other fits in Table S1 yields very similar simulations.
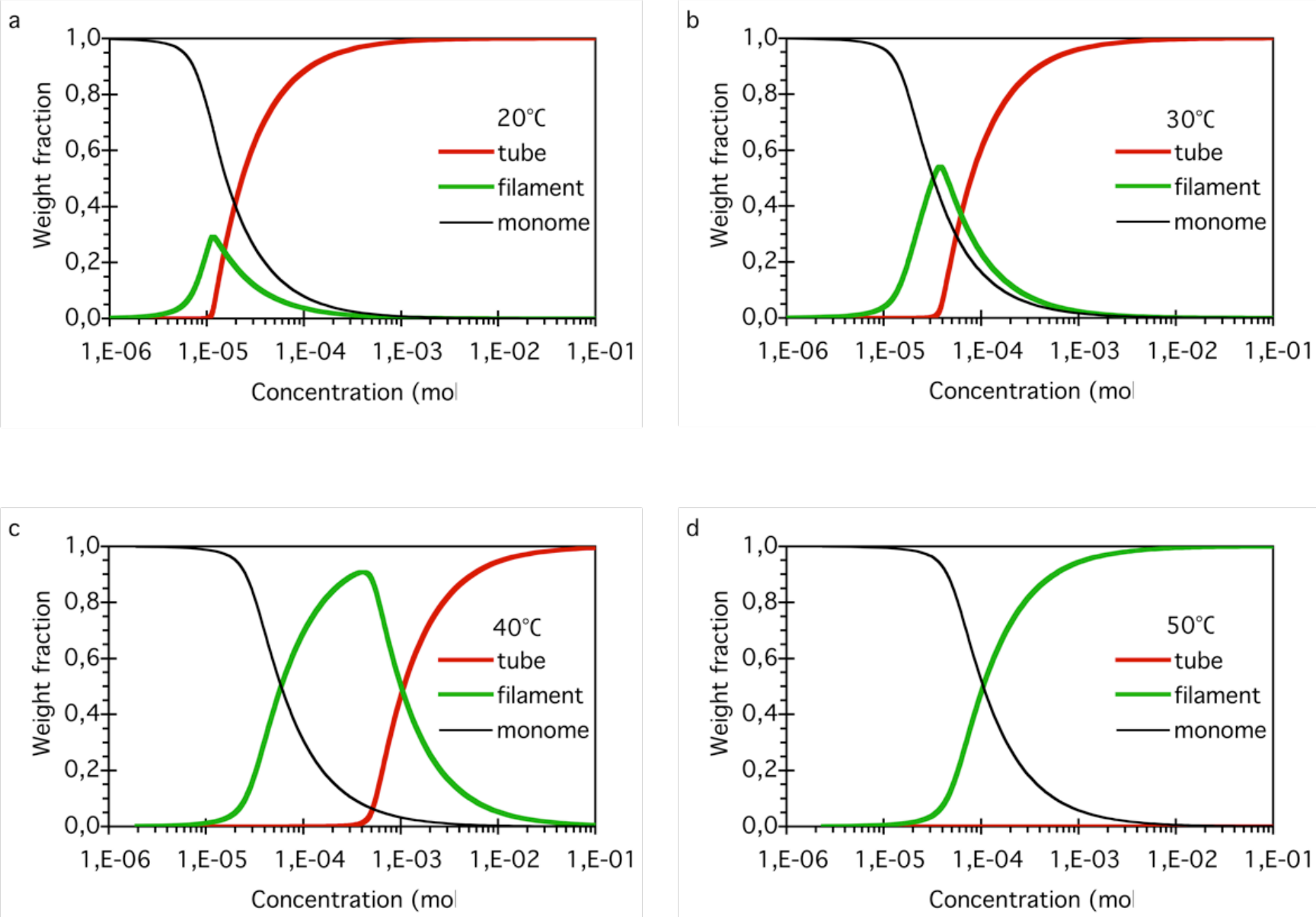

Figure 6. Calculated weight fractions of monomers, filaments and tubes for EHUT solutions in toluene, versus overall concentration, at several temperatures. The calculated values are based on the association model and the parameter values in Table 1. 

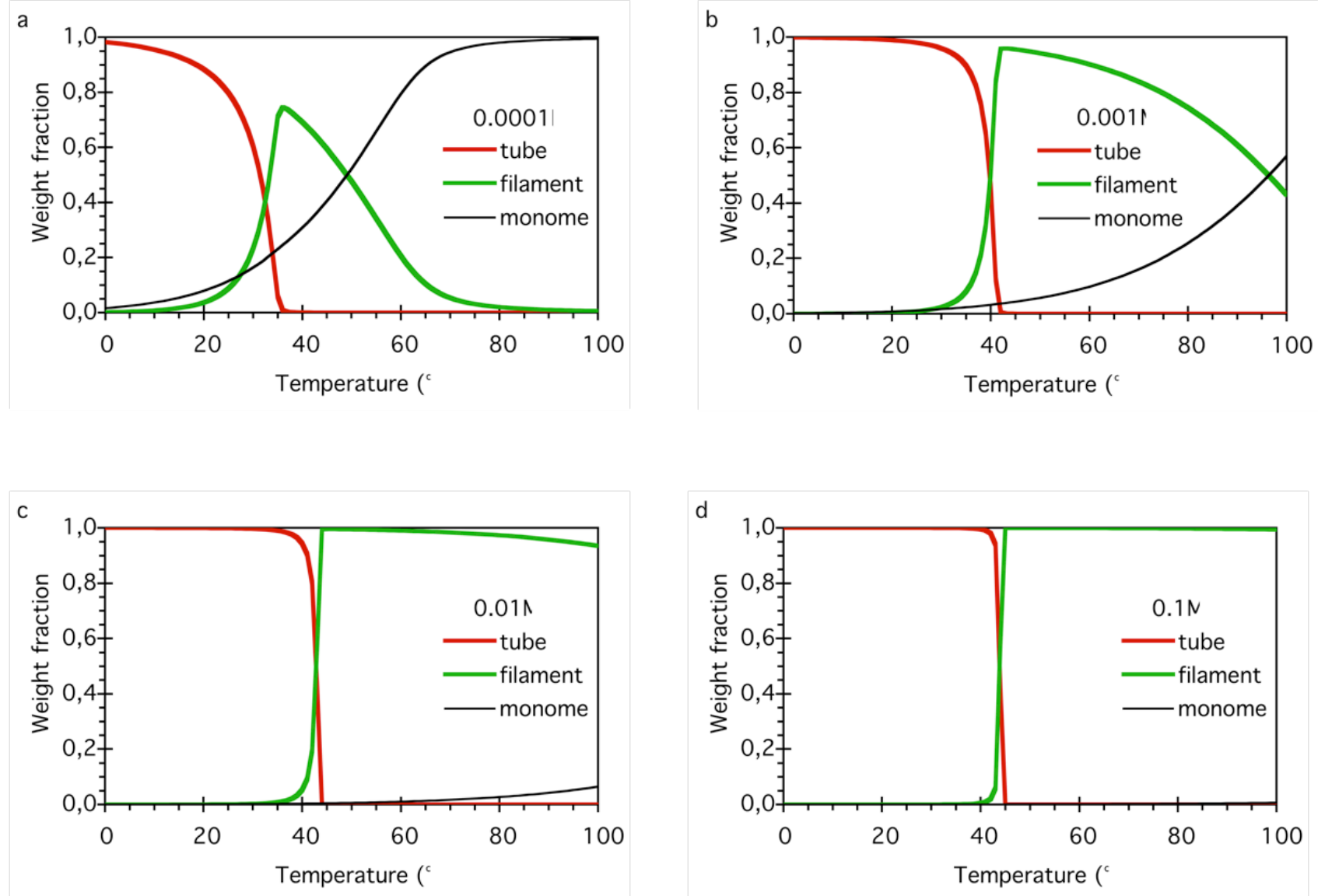

Figure 7. Calculated weight fractions of monomers, filaments and tubes for EHUT solutions in toluene, versus temperature, at several concentrations. The calculated values are based on the association model and the parameter values in Table 1.

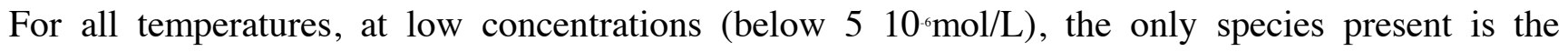
monomer (Figure 6). At high concentration (above $10^{-2} \mathrm{~mol} / \mathrm{L}$ ), the species present nearly exclusively is either the tube (below $40^{\circ} \mathrm{C}$ ) or the filament (above $45^{\circ} \mathrm{C}$ ). The transition between the two regions is very sharp (Figure 7c and 7d), which is in agreement with previous FTIR data. ${ }^{6}$ At intermediate concentrations however, the transitions are much more gentle: there is a large range of temperatures and concentrations where monomers, filaments and tubes are present in comparable proportions: the pseudophase diagram (Figure 3) only shows the regions where a given species is the most abundant; it does not necessarily mean that the other species have negligible concentrations. 
Figures 8 and 9 show the number average degree of polymerization and curvilinear length of filaments and tubes versus concentration (Figure 8) or temperature (Figure 9). The length was calculated from the degree of polymerization and the linear density of filaments or tubes determined by SANS (see Supporting Information). The most important comment is the huge length of tubes: according to our present association model, the tubes reach micrometer lengths, at concentrations in the millimolar range (Figure 8a).
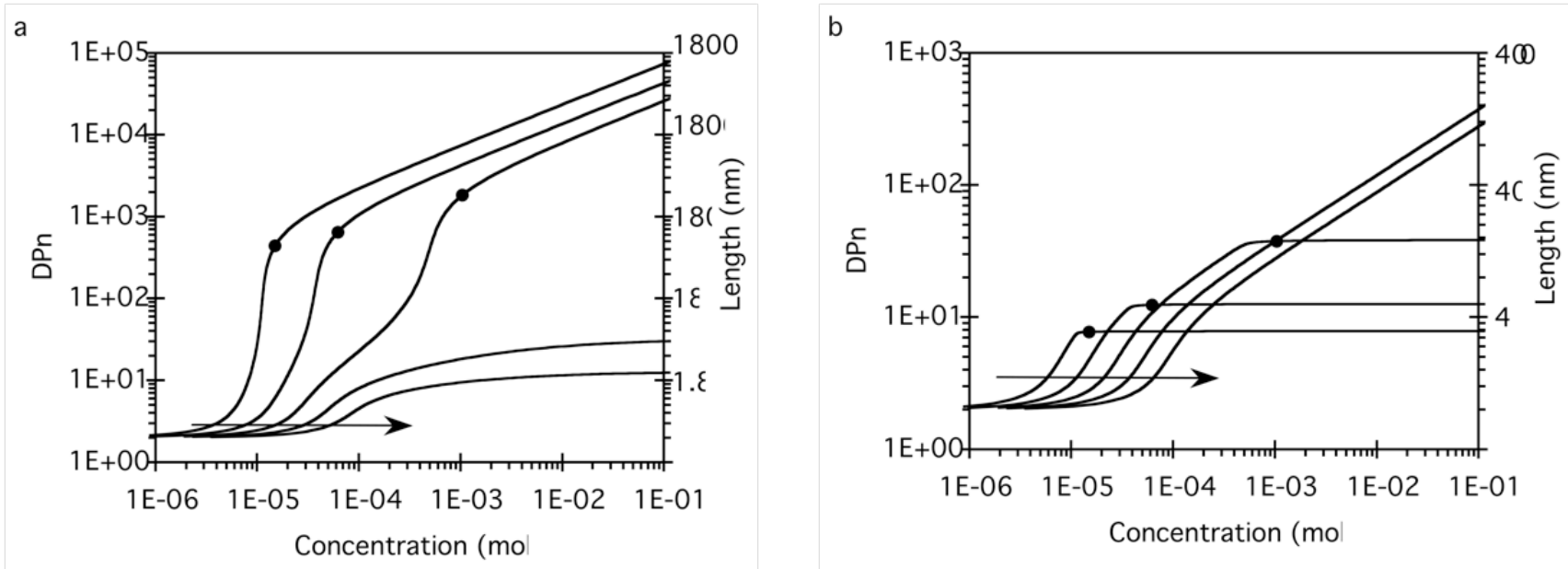

Figure 8. Calculated number average degree of polymerization and curvilinear length of the tube fraction (a) or the filament fraction (b) for EHUT solutions in toluene at 20, 30, 40, 50 and $60^{\circ} \mathrm{C}$. The black points visualize the concentration above which tubes are predominant $\left(\mathrm{c}^{* *}\right)$; the arrows show the order of increasing temperatures. The calculated values are based on the association model and the parameter values in Table 1.

In fact, it is possible to semi-quantitatively check this information by comparing to viscosity data. Previous measurements showed that the viscosity of EHUT solutions in toluene at $25^{\circ} \mathrm{C}$ increases steeply at a concentration of $6 \pm 110^{-4} \mathrm{~mol} / \mathrm{L} \cdot{ }^{19 \mathrm{~b}}$ This concentration corresponds to the overlap of the supramolecular chains and is related to the length of the chains. The overlap concentration $\left(\mathrm{C}_{0}^{*}\right)$ is reached when the local concentration inside a sphere containing a single chain is equal to the 
macroscopic concentration..$^{38}$ Then, if we assume that the tubes are the main species present and that they are straight rods:

$$
C_{0}^{*}=\frac{D P_{n}(\text { tube })}{\frac{4 \pi}{3}\left(\frac{L(\text { tube })}{2}\right)^{3} N_{A}}
$$

where $N_{\mathrm{A}}$ is the Avogadro number, and the length of the tubes is

$$
L(\text { tube })=\frac{D P_{n}(\text { tube })}{n_{L}(\text { tub })}
$$

where $n_{\llcorner}$is the linear density determined by SANS ( $n_{\llcorner}($tube $)=0.55 \AA^{-1}$, see Supporting Information). Rearranging Eqs (8) and (9) yields

$$
L(\text { tube })=\sqrt{\frac{610^{25} n_{L}(\text { tub })}{\pi C_{0}^{*} N_{A}}}
$$

Thus, the viscosity measurements show that the length of the tubes at the overlap concentration of $C_{0}^{*}=$ $610^{-4} \mathrm{~mol} / \mathrm{L}$ is $\mathrm{L}($ tube $)=170 \mathrm{~nm}$, if the latter are perfect rods. If the tubes are not perfectly rigid over this length scale, then $\mathrm{L}($ tube $) \geq 170 \mathrm{~nm}$. This analysis shows that the value deduced from the association model is of the right order of magnitude: at $\mathrm{T}=25^{\circ} \mathrm{C}$ and $\mathrm{C}_{0}=610^{-4} \mathrm{~mol} / \mathrm{L}$, the calculated length of the tubes is $770 \pm 400 \mathrm{~nm}$.
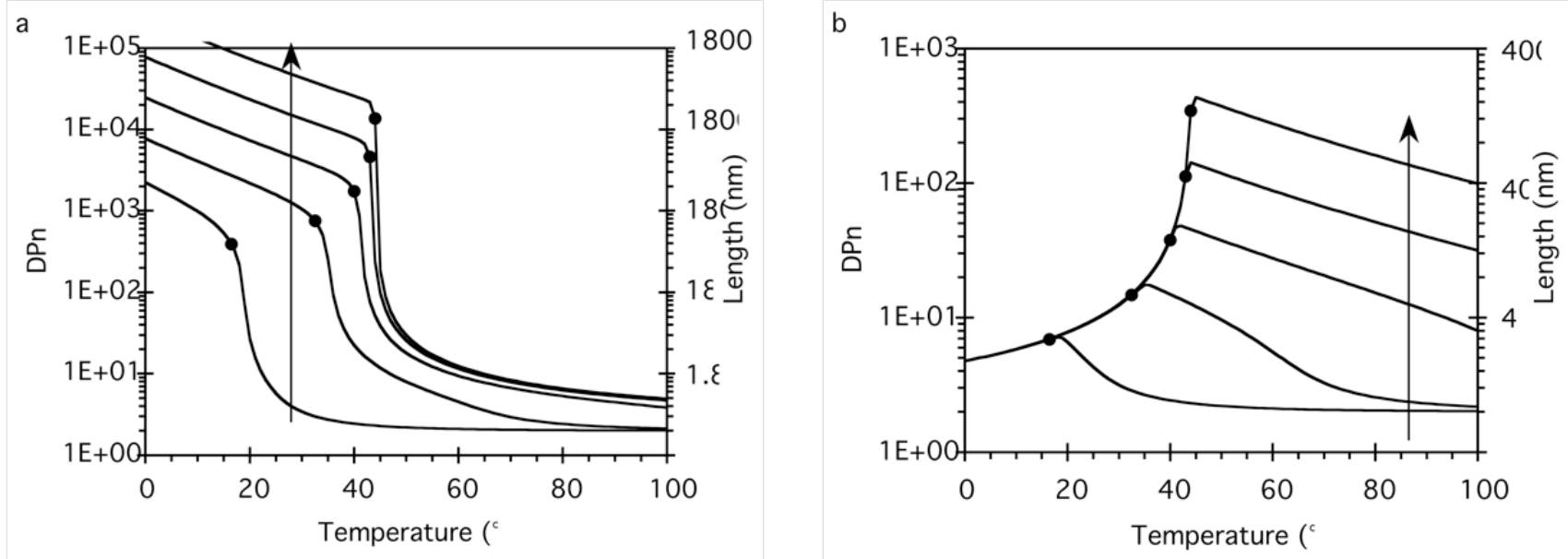

Figure 9. Calculated number average degree of polymerization and curvilinear length of the tube fraction (a) or the filament fraction (b) for EHUT solutions in toluene at $10^{-5}, 10^{-4}, 10^{-3}, 10^{-2}$ and $10^{-1} \mathrm{~mol} / \mathrm{L}$. 
The black points visualize the temperature below which tubes are predominant $\left(\mathrm{T}^{* *}\right)$; the arrows show the order of increasing concentrations. The calculated values are based on the association model and the parameter values in Table 1.

Furthermore, comparison between Figures $8 \mathrm{a}$ and $8 \mathrm{~b}$ reveals that the tubes reach much larger degrees of polymerization than the filaments, at appropriate concentrations and temperatures. This may seem in contradiction with the fact that the association constants $\mathrm{K}$ and $\mathrm{k}$ are of the same order of magnitude (Table 1), because in the usual case of isodesmic growth $\left(\mathrm{K}_{2}=\mathrm{K}\right)$, the degree of polymerization is proportional to $\left(\mathrm{C}_{0} \mathrm{~K}\right)^{0.5}{ }^{4}$ However, in the case of cooperative systems $\left(\mathrm{K}_{2}<<\mathrm{K}\right)$, it has been shown that the best measure of the strength of the association is neither $K_{2}$ nor $K$, but $K^{2} / K_{2}$, which is the association constant between two chains. ${ }^{195}$ In fact, Figures S6 and S7 show that when the tubes are the main species present in solution, then the degree of polymerization of the tubes is close to $\left(\mathrm{C}_{0} \mathrm{~K}^{2} / \mathrm{K}_{2}\right)^{0.5}$. Similarly, when the filaments are the main species present in solution, then the degree of polymerization of the filaments is close to $\left(\mathrm{C}_{0} \mathrm{k}^{2} / \mathrm{k}_{2}\right)^{05}$. Therefore, the tubes can reach much larger degrees of polymerization than the filaments, because of the higher cooperativity of their formation $\left(K / K_{2}>k / k_{2}\right)$. This higher cooperativity for the tubes is in turn probably due to the fact that the size of the nucleus above which growth is stabilized, is larger for the tri-molecular tubes than for the mono-molecular filaments.

Another result shown by Figure 8 is the fact that at temperatures below $40^{\circ} \mathrm{C}$, the growth of the filaments is stopped when the tubes become the main species. This phenomenon has previously been described in the case of peptide self-assembly into single and double $\beta$-sheets. ${ }^{27} \mathrm{~A}$ direct consequence is that in a limited temperature range, it is possible that an increase in temperature leads to a counterintuitive increase in the filament length (Figure 9b), because in this temperature range the tube fraction disappears to the benefit of the filaments.

\section{Conclusion}

We have reported an association model describing the self-assembly of a supramolecular polymer into two competing forms. The parameters controlling the system have been measured by high sensitivity DSC and ITC in the case of a hydrogen-bonded bis-urea supramolecular polymer. The model enables to 
compute the proportion and length of all components in the system at any temperature and concentration. The results of these calculations are in agreement with the experimental phase diagram and with independent viscosity measurements.

Supporting Information Available: Additional data concerning the DSC experiments and the ITC fitting procedure. This information is available free of charge via the Internet at http://pubs.acs.org.

\section{References}

(1) Zimmerman, N.; Moore, J. S.; Zimmerman, S. C. Chem. Ind. 1998, 604-610.

(2) Brunsveld, L.; Folmer, B. J. B.; Meijer, E. W.; Sijbesma, R. P. Chem. Rev. 2001, 101, 4071-4097.

(3) Supramolecular Polymers; Ciferri, A., Ed.; Marcel Dekker, Inc.: New York, 2005.

(4) Bouteiller, L. Adv. Polym. Sci. 2007, 207, 79-112.

(5) Cordier, P.; Tournilhac, F.; Soulie-Ziakovic, C.; Leibler L. Nature, 2008, 451, 977-980.

(6) Bouteiller, L.; Colombani, O.; Lortie, F.; Terech, P. J. Am. Chem. Soc. 2005, 127, 8893-8898.

(7) Pinault, T.; Isare, B.; Bouteiller, L. Chem. Phys. Chem. 2006, 7, 816-819.

(8) Shikata, T.; Nishida, T.; Isare, B.; Linares, M.; Lazzaroni, R.; Bouteiller, L. J. Phys. Chem. B 2008, $112,8459-8465$.

(9) (a) Boileau, S.; Bouteiller, L.; Lauprêtre, F.; Lortie, F. New J. Chem. 2000, 24, 845. (b) Lortie, F.; Boileau, S.; Bouteiller, L.; Chassenieux, C.; Demé, B.; Ducouret, G.; Jalabert, M.; Lauprêtre, F.; Terech, P. Langmuir 2002, 18, 7218-7222. (c) Ducouret, G.; Chassenieux, C.; Martins, S.; Lequeux, F.; Bouteiller, L. J. Coll. Interface Sci. 2007, 310, 624.

(10) (a) van der Gucht, J.; Besseling, N. A. M.; Knoben, W.; Bouteiller, L.; Cohen Stuart, M. A. Phys. Rev. E 2003, 67, 051106. (b) Knoben, W.; Besseling, N. A. M.; Bouteiller, L.; Cohen Stuart, M. A. Phys. Chem. Chem. Phys. 2005, 7, 2390. (c) Knoben, W., Besseling, N. A. M.; Cohen Stuart, M. A. Phys. Rev. Lett. 2006, 97, 068301. (d) Knoben, W.; Besseling, N. A. M.; Cohen Stuart, M. A. Langmuir 
2007, 23, 6095. (e) Knoben, W.; Besseling, N. A. M.; Cohen Stuart, M. A. J. Chem. Phys. 2007, 126, 024907.

(11) Chodorowski-Kimmes, S.; Livoreil, A.; Baghdadli, N.; Rodriguez, I. EP 1787681, 2007. Chodorowski-Kimmes, S.; Baghdadli, N.; Arnaud-Roux, M.; Garipova, G.; Bouteiller, L. EP 1797864, 2007. Chodorowski-Kimmes, S. EP 1864649, 2007.

(12) Martin, R. B. Chem. Rev. 1996, 96, 3043-3064.

(13) Sijbesma, R. P.; Beijer, F. H.; Brunsveld, L.; Folmer, B. J. B.; Hirschberg, J. H. K. K.; Lange, R. F. M.; Lowe, J. K. L.; Meijer, E. W. Science 1997, 278, 1601-1604.

(14) Würthner, F.; Thalacker, C.; Sautter, A.; Schärtl, W.; Ibach, W.; Hollricher, O. Chem. Eur. J. $\mathbf{2 0 0 0}, 6,3871-3886$.

(15) Berl, V.; Schmutz, M.; Krische, M. J.; Khoury, R. G.; Lehn, J.-M. Chem. Eur. J. 2002, 8, $1227-$ 1244.

(16) Xu, J.; Fogleman, E. A.; Craig, S. L. Macromolecules 2004, 37, 1863-1870.

(17) Stoncius, S.; Orentas, E.; Butkus, E.; Ohrström, L.; Wendt, O. F.; Wärnmark, K. J. Am. Chem. Soc. 2006, 128, 8272-8285.

(18) Jadzyn, J.; Stockhausen, M.; Zywucki, B. J. Phys. Chem. 1987, 91, 754-757.

(19) (a) Boileau, S.; Bouteiller, L.; Lortie, F. Chem. Eur. J. 2003, 9, 3008-3014. (b) Simic, V.; Bouteiller, L.; Jalabert, M. J. Am. Chem. Soc. 2003, 125, 13148-13154. (c) Colombani, O.; Bouteiller, L. New J. Chem. 2004, 28, 1373-1382.

(20) Zhao, D.; Moore, J. S. Organic Biomolecular Chemistry 2003, 1, 3471-3491.

(21) (a) Jonkheijm, P.; van der Schoot, P.; Schenning, A. P. H. J.; Meijer, E. W. Science 2006, 313, 80-83. (b) Mulders, M. M. J.; Schenning, Albertus P. H. J.; Meijer, E. W. J. Am. Chem. Soc. 2008, 130, 606-611 
(22) Arnaud, A.; Belleney, J.; Boué, F.; Bouteiller, L.; Carrot, G.; Wintgens, V. Angew. Chem. Int. Ed. 2004, 43, 1718-1721.

(23) Odille, F. G. J.; Jonsson, S.; Stjernqvist, S.; Ryden, T.; Wärnmark, K Chem. Eur. J. 2007, 13, 9617-9636.

(24) (a) Ercolani, G. J. Phys. Chem. B 1998, 102, 5699-5703. (b) Ercolani, G.; Ioele, M.; Monti, D. New J. Chem. 2001, 25, 783-789.

(25) (a) Abed, S.; Boileau, S.; Bouteiller, L.; Lacoudre, N. Polymer Bulletin, 1997, 39, 317-324. (b) Abed, S.; Boileau, S.; Bouteiller, L. Macromolecules 2000, 33, 8479-8487. (c) Abed, S.; Boileau, S.; Bouteiller, L. Polymer, 2001, 42, 8613-8619.

(26) Gibson, H. W.; Yamaguchi, N.; Jones, J. W. J. Am. Chem. Soc. 2003, 125, 3522-3533.

(27) (a) Nyrkova, I. A.; Semenov, A. N.; Aggeli, A.; Bell, M.; Boden, N.; McLeish, T. C. B. Eur. Phys. J. B 2000, 17, 499-513. (b) Aggeli, A.; Nyrkova, I. A.; Bell, M.; Harding, R.; Carrick, L.; McLeish, T. C. B.; Semenov, A. N.; Boden, N. Proc. Nat. Acad. Sci. USA 2001, 98, 11857-11862.

(28) Arnaud, A.; Bouteiller, L. Langmuir 2004, 20, 6858-6863.

(29) The $\mathrm{K}_{2}, \mathrm{~K}$ model for the tubes is clearly a crude approximation. Indeed, the proposed tubular structure $^{78}$ means that the hexamer is expected to be much more stable than all shorter oligomers. Consequently, a nucleus of size 6 would make more sense than a nucleus of size 2 . However, including this point in the model would significantly complicate the equations. Our present aim is to find the simplest possible model accounting for the experimental results.

(30) As reviewed by Ciferri, ${ }^{3}$ excluded volume interactions may be responsible for a coupling between supramolecular growth and tube orientation. In the present system, no birefringence was detected in the absence of flow; therefore, the effect of excluded volume interactions was neglected in the model.

(31) Biocalorimetry. Applications of Calorimetry in the Biological Sciences; Ladbury, J. E., Chowdhry, B. Z., Eds.; John Wiley \& Sons: Chichester, U.K., 1998. 
(32) (a) Guenet, J.-M. Thermochim. Acta 1996, 284, 67-83. (b) Liu, W.; Guenet, J.-M.; Green, M. M. Chirality 2004, 16, 661-664.

(33) Peles-Lemli, B.; Peles-Lemli, J.; Bitter, I.; Kollar, L.; Nagy, G.; Kunsagi-Mate, S. J. Incl. Phenom. Macrocycl. Chem. 2007, 59, 251-256.

(34) Brunsveld, L.; Zhang, H.; Glasbeek, M.; Vekemans, J. A. J. M.; Meijer, E. W. J. Am. Chem. Soc. $2000,122,6175-6182$.

(35) ITC experiments cannot be performed at higher concentrations because of the high viscosity of the solutions, and FTIR experiments cannot be performed at lower concentrations because of insufficient sensitivity.

(36) Self-association of ureas in general and bis-urea EHUT in particular have been shown to be highly cooperative: $\mathrm{K}_{2} \ll \mathrm{K}$. Therefore, except if the entropy for dimerization is much more unfavorable than for oligomerization, then: $-\Delta \mathrm{H}_{2}<-\Delta \mathrm{H}$.

(37) In a previous publication, the experimental transition between filaments and free monomers was somewhat arbitrarily chosen as the mid-point of the ITC heat-flow jump. ${ }^{6}$ However, if we define the critical concentration $\left(\mathrm{c}^{*}\right)$ as the point where the free monomer concentration is equal to the total filament concentration, then calculations show that $\mathrm{c}^{*}$ is closer to twice the mid-point of the heat-flow jump (see Figures S4 and S5).

(38) Scaling Concepts in Polymer Physics; de Gennes, P.-G.; Cornell University Press: Ithaca, 1979. 
For Table of Contents Use Only

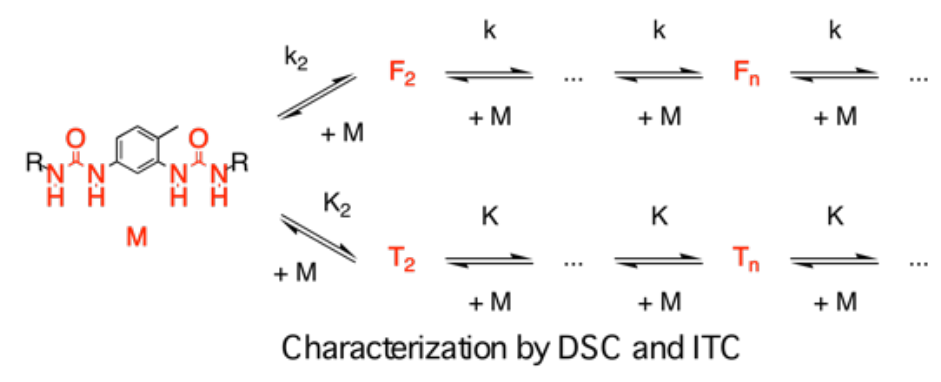

